Research Article

\title{
The Dynamic Response Law of Bank Slope under Water-Rock Interaction
}

\author{
Yinchai Zhang, Huafeng Deng ${ }^{D}$, Wei Wang, Lingling Duan, Yongyan Zhi, and Jianlin Li \\ Key Laboratory of Geological Hazards on Three Gorges Reservoir Area of Ministry of Education, China Three Gorges University, \\ Yichang, Hubei, China
}

Correspondence should be addressed to Huafeng Deng; dhf8010@ctgu.edu.cn

Received 16 April 2018; Accepted 16 July 2018; Published 7 August 2018

Academic Editor: Fengqiang Gong

Copyright $(92018$ Yinchai Zhang et al. This is an open access article distributed under the Creative Commons Attribution License, which permits unrestricted use, distribution, and reproduction in any medium, provided the original work is properly cited.

During the reservoir operation process, the long-term security and stability of the bank slope is affected by dynamic response characteristics of its seismic action directly. Aimed at the typical bank slope existing in the actual reservoir environment, an experiment considering reservoir water level fluctuation and soaking-air-drying cyclic water-rock interaction has been designed and conducted while the cyclic loading test was performed in different water-rock cycles. Research results indicate the following: Firstly, in the process of water-rock interaction, the dynamic characteristics of sandstone show evident degradation trend, with the increase of the damping ratio and Poisson's ratio and decrease of dynamic elastic modulus, and the former six water-rock cycle degradation effects are particularly obvious. Secondly, the numerical analog computation analysis of dynamic response in typical bank slope shows that as the water-rock interaction period is increased, the dynamic response of the slope hydro-fluctuation belt zone increases gradually, while the other parts weaken. Thirdly, under the long-term water-rock interaction process, the hydrofluctuation belt zone gradually becomes a "soft layer" which is sensitive to the earthquake effect and dynamic response, resulting in a direct influence on long-term seismic performance of the bank slope. Therefore, it is necessary to make better protection for the bank slope hydro-fluctuation belt zone.

\section{Introduction}

In the process of hydraulic and hydroelectric engineering construction, reservoir impoundment will change geological and mechanical conditions naturally formed over the years [1]. This has triggered series of new geological disasters, one of which is inevitable reservoir earthquake. The reservoir earthquakes can be classified as karst type, ore collapse type, and superficial stress adjustment type [2]. And, some of the reservoir earthquake mechanisms are related to their hydrogeological structure and the nearby fault coulomb stress [3], while the others correspond with karst effect [4]. Recent research results show that small earthquakes in the Three Gorges Reservoir Area appeared to be linear or clumpy distribution [5].

For example, a 6.1 magnitude earthquake that occurred near Xinfengjiang reservoir in 1962 caused significant damage to its dam. Since the impoundment of the Three Gorges Reservoir on June 2003, a series of reservoir earthquakes ensued along the river section in Zigui and Badong County, which has reached over ten thousand times so far. Most of them are small earthquakes below the level of 3-4, and the magnitude of 4.0 or above has occurred six times. On December 16, 2013, a 5.1 magnitude earthquake occurred in Badong County of the Three Gorges reservoir area, with a depth of $5.0 \mathrm{~km}$ and about 100 kilometers from the Three Gorges Dam. It was the largest earthquake since the impoundment of the Three Gorges Reservoir. Analysis indicates that its recorded seismic waveform has long period with more low-frequency components and less highfrequency ones. Except for deformation and damage of hydraulic structures, like the rock collapse in the higher water pressure $[6,7]$, reservoir-induced earthquake also generates significant impacts on the deformation and safety of the bank slopes. Thus, the dynamic response to the seismic action of the bank slope plays an important role in the long-term deformation and stability analysis. In the dynamic response analysis of the bank slope, it is necessary 
to consider the influence of reservoir water on the dynamic characteristics.

Previous studies on water-rock interaction show that the saturated condition or dry-wet circulation influenced obviously the static characteristics of rock mass. Liu et al. [8], Fu et al. [9], Yao et al. [10], Jiang et al. [11], Hale and Shakoor [12], and Zhu et al. [13] successively carried out a series of drywet cycling tests on sandstone and shale, whose results indicated that distinct degradation generated on the rock's strength parameters during the dry-wet circulation. Jeng et al. [14] and Lin et al. [15] studied the microscopic mechanism of sandstone degradation under the dry-wet circulation. They found that the sandstone strength decreased obviously under the dry-wet circulation and the porosity increased in the nonlinear form. Combined with self-designed rock soak device YRK-1 to simulate repeated fluctuation of water level from $145 \mathrm{~m}$ to $175 \mathrm{~m}$, Deng et al. [16-19] carried out the water-rock test considering changes in water pressure and soaking dry cycle, which indicated that water-rock damage is greatly affected by the varied soaking water pressure.

Research results above indicate that the water-rock interaction of the bank slope has obvious weakening effect on its static characteristics, and this effect shows distinct accumulation and timeliness. So, does the rock dynamic response under water-rock interaction fit with the similar variation law?

From the current research of the water-rock interaction, most of the works mainly focus on the rock static characteristics degradation law, with the rare study of its dynamic characteristics. The rock dynamic parameter deterioration influenced by water-rock interaction is also less considered in the long-term evaluation of the bank slope stability.

In this paper, the typical bank slope was selected as the object from the Three Gorges Reservoir Area. Considering the repeated fluctuation of the reservoir water level and the process of soaking-air-drying circulation, the water-rock interaction test is designed and carried out. The cyclic loading and unloading tests were performed in different water-rock interaction cycles, for the analysis of sandstone dynamic characteristics degradation rule. By the numerical simulation calculation of FLAC3D software on the dynamic module, the research on the slope dynamic response under long-term water-rock interaction was carried out in this paper.

\section{Experimental Programs}

2.1. Sample Preparation. Originating from the bank slope of Baishuihe in the Three Gorges Reservoir Area, known as weak weathering sandstone with medium-grained quartz inside, a sample was selected as the rock sample in this paper. According to the standard requirements [20] in the Specifications in the Testing Method of Engineering Rock Mass (GB/T 50266-2013), the standard rock samples with a diameter of $50 \mathrm{~mm}$ and a height of $100 \mathrm{~mm}$ are prepared. After the longitudinal wave velocity and mass measurement, the rock samples with relative concentration of wave velocity and density are selected as test samples. Typical test rock samples are shown in Figure 1.

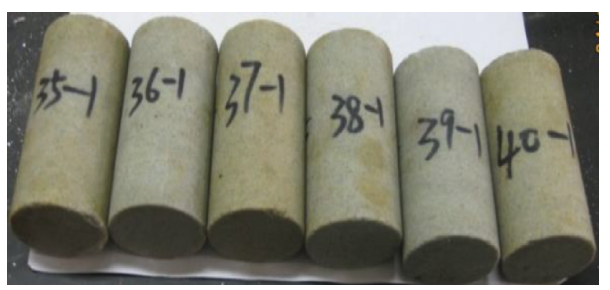

FIgURE 1: Typical samples of sandstone.

2.2. The Water-Rock Interaction Test Scheme. According to the operation requirements of the Three Gorges Reservoir, the water level of the reservoir fluctuates between $145 \mathrm{~m}$ and $175 \mathrm{~m}$ each year after its completion, which generates the hydro-fluctuation belt with a height of $30 \mathrm{~m}$ between the two sides of the $600 \mathrm{~km}$ long channel. It is a typical zone affected greatly by water-rock interaction. Under substantial fluctuation of the reservoir water, the reservoir water supplies groundwater occasionally and sometimes supplies the others in the reverse order, which generate alternate state of soaking and dewatering in the rock mass of the hydrofluctuation belt. This alternate effect is a kind of "fatigue" $[21,22]$ for rock mass resulting in its property degradation; each of the processes may not be significant enough, but cumulative damage effect will develop through numerous repeated processes of soaking and dewatering. In other words, the hydro-fluctuation belt is a sensitive deformation zone of the bank slope. Therefore, mainly considering the water-rock interaction of the hydro-fluctuation belt, it is crucial to simulate the change process of the soaking water pressure, including rising process, consistent process, declining process, and the natural air drying process after that. Hence, as is shown in Figure 2, the self-developed YRK-2 rock immersion-air-dry circulation test instrument was used to simulate the water pressure fluctuation and soak-air-dry cycle process. This instrument realizes the water-rock interaction process such as pressure soaking and temperature controlled air-drying, with automatic collection of parameters like water pressure and temperature.

According to the previous experimental experience, the experiment scheme of soaking-air-dry circulation to simulate water-rock interaction process was designed, and the process is shown in Figure 3. A single water-rock cycle lasts for 40 days and is divided into two stages: the first stage is the soaking period-firstly, the samples are soaked in a container filled with water for 10 days; during the time, water pressure increases to $0.3 \mathrm{MPa}$ (to simulate the water level rise from $145 \mathrm{~m}$ to $175 \mathrm{~m}$ ), then the water pressure remains unchanged for 10 days (to simulate the constant water level of $175 \mathrm{~m}$ ), and in the end, the uniform water pressure reduces uniformly to 0 within the last 10 days (to simulate the water level decrease from $175 \mathrm{~m}$ to $145 \mathrm{~m}$ ); the second stage is the air-drying stage, during which rock samples are soaked in a container with the constant temperature of $35^{\circ} \mathrm{C}$ (simulation process of dry during low initial water level) and then air dried for 10 days. Then, the soak-air-dry procedure is repeated, and the total design cycle is 10 times. For the study of the dynamic characteristics of the sample degradation rule at different water-rock cycles, cyclic loading and 


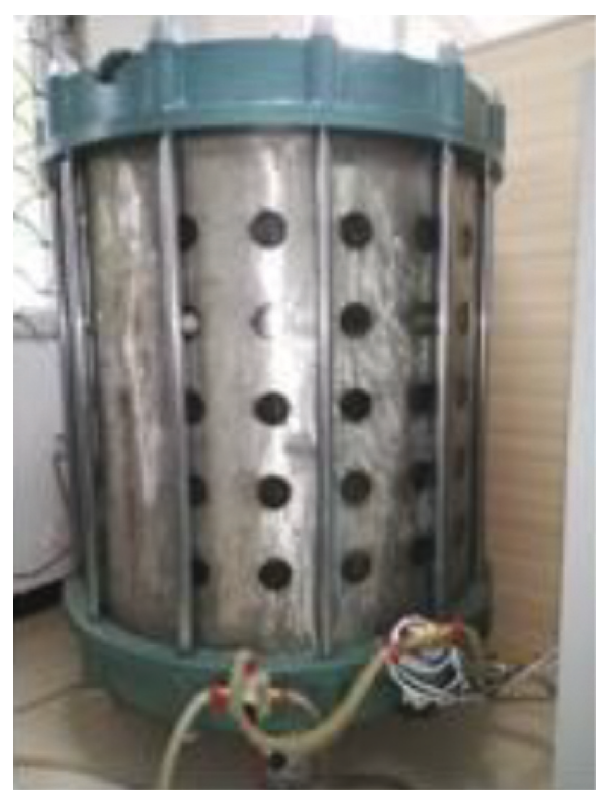

(a)

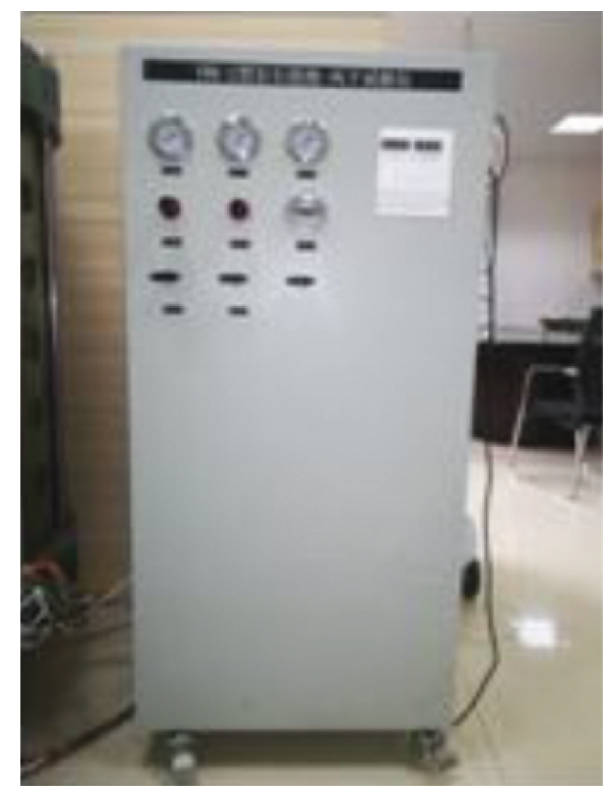

(b)

FIGURE 2: YRK-2 rock immersion air-dry tester: (a) soaking container; (b) control cabinet.

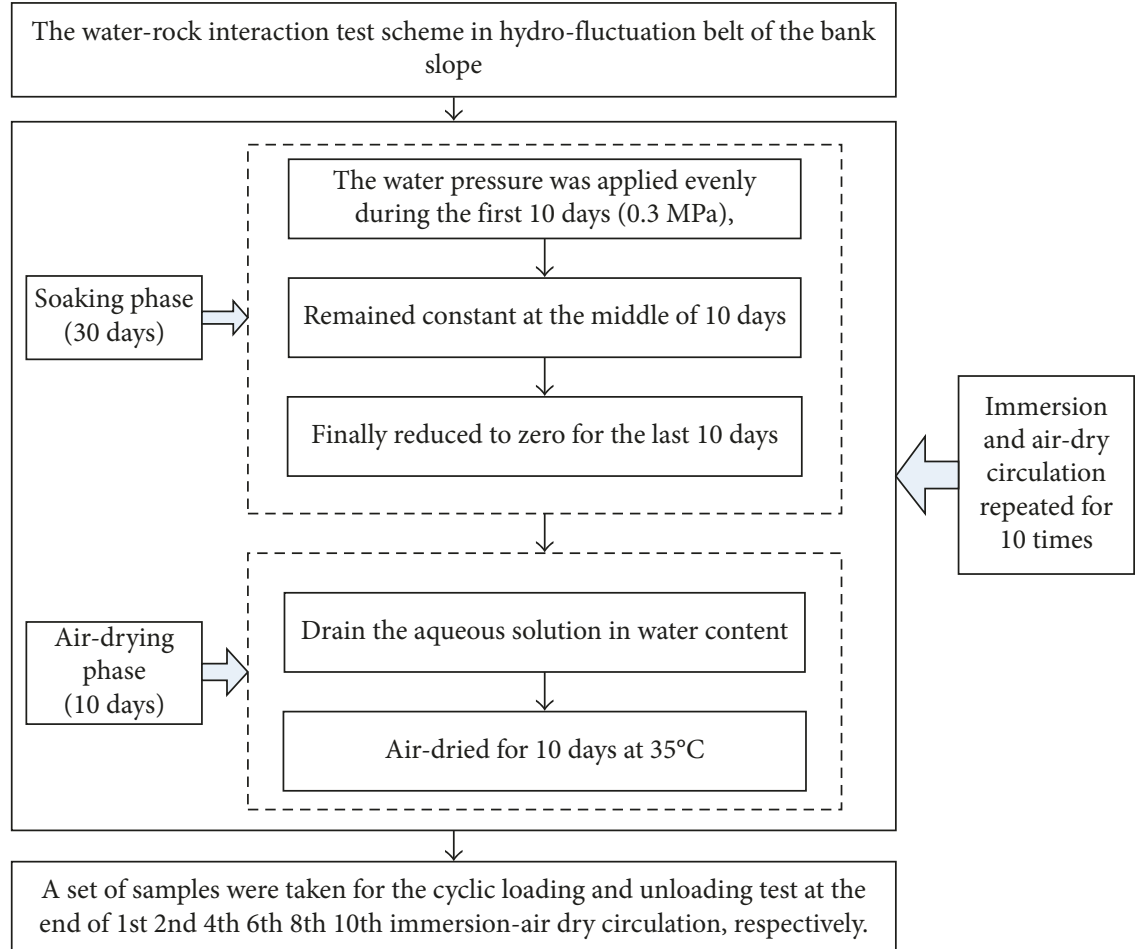

FIGURE 3: Test process diagram of water-rock interaction of the bank slope.

unloading experiments and the uniaxial compression test were performed on a set of samples selected separately at the end of 1st, 2nd, 4th, 6th, 8th, and 10th cycle of soaking.

2.3. The Cyclic Loading and Unloading Test Scheme. As for the seismic simulation test, cyclic loading and unloading tests are the most common ones in the laboratory. Previous research shows that the accumulation of irreversible deformation of rock, growth trend, and total fatigue under cyclic loading is directly related to fatigue damage [23]. According to the standard requirements [24, 25], saturated rock uniaxial compressive strength is about $50 \mathrm{MPa}$, and the constant loop unloading test was carried out considering the frequent emergence of reservoir earthquake with low frequency and magnitude [26]. The lower and upper limits of 
cyclic load stress are, respectively, defined as $10 \mathrm{MPa}$ and $20 \mathrm{MPa}$, which refer to $20 \%$ and $50 \%$ of rock uniaxial compressive strength [27]. The sine wave repeated 30 times was used for cyclic loading and unloading tests, with a frequency of $0.1 \mathrm{~Hz}$. Typical cyclic loading and unloading stress-strain curve is shown in Figure 4.

As is shown in Figure 5, the RMT-150CROCk Mass Zesting system is used to carry out the cyclic test. It can switch from different load models including displacement, time, and their combination, which is suitable for uniaxial or triaxial compression unloading circulation tests, and so on.

\section{Analysis of the Sandstone Dynamic Characteristics Deterioration under Water-Rock Interaction}

3.1. Calculation Principle of Rock Dynamic Parameters under Cyclic Loading and Unloading Test. In the loading and unloading circulation process, the stress-strain curve often developed hysteresis loop due to the nonideal elastic medium of the rock, as is shown in Figure 6. Damping ratio and dynamic elastic modulus are defined [28] in the following equations:

$$
\begin{aligned}
\lambda & =\frac{A_{\mathrm{R}}}{4 \pi A_{\mathrm{s}}}, \\
E_{\mathrm{d}} & =\frac{\sigma_{\mathrm{d} \max }-\sigma_{\mathrm{d} \min }}{\varepsilon_{\mathrm{d} \max }-\varepsilon_{\mathrm{d} \min }} .
\end{aligned}
$$

3.2. Analysis of the Sandstone Dynamic Characteristics Deterioration Rule under the Water-Rock Interaction. To facilitate the comparison analysis of sample's characteristics degradation effect in different water-rock circulations, the 16th stress-strain hysteresis loop was voted as calculation for the related rock dynamic parameters. The variation curves of damping ratio, dynamic modulus of elasticity, and passion ratio are as given in Figures 7-9, respectively.

As is depicted in Figure 7, the damping ratio of the rock sample increased gradually as water-rock interaction process increased. After the 1st, 2nd, 4th, 6th, 8th, and 10th cycles of immersion air-dry, damping ratio increased to $7.71 \%$, $14.49 \%, 20.55 \%, 22.81 \%, 24.35 \%$, and $25.45 \%$, respectively. The curve of the damping ratio grew fast during the first six immersion air-dry cycles and then gradually tended to be slow, which shares the similar law with the static strength deterioration and deformation tendencies of sandstone [16-19].

As is depicted in Figure 8, the dynamic elasticity modulus of the rock sample decreased gradually as waterrock interaction process increased. After the 1st, 2nd, 4th, 6 th, 8 th, and 10th cycles of immersion air-dry, the dynamic elasticity modulus decreased to $8.23 \%, 15.80 \%, 22.10 \%$, $26.52 \%, 28.35 \%$, and $29.42 \%$, respectively. The curve of the dynamic elasticity modulus declined fast during the first six immersion air-dry cycles and then gradually tended to be slow.

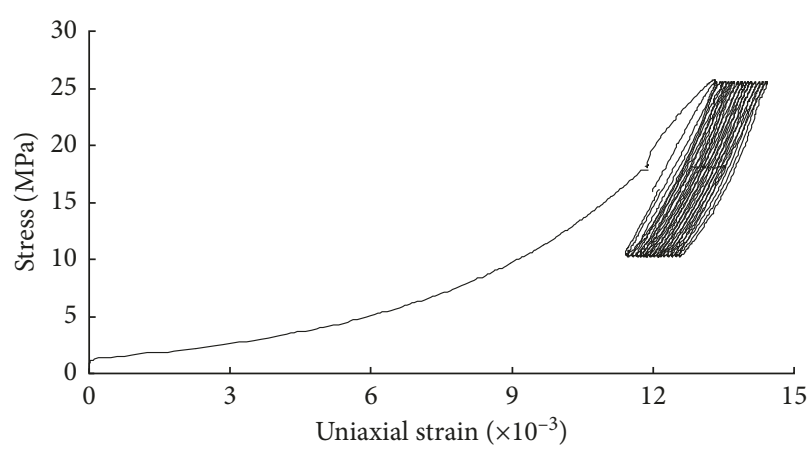

FIgURE 4: Typical cyclic loading and unloading stress-strain curve.

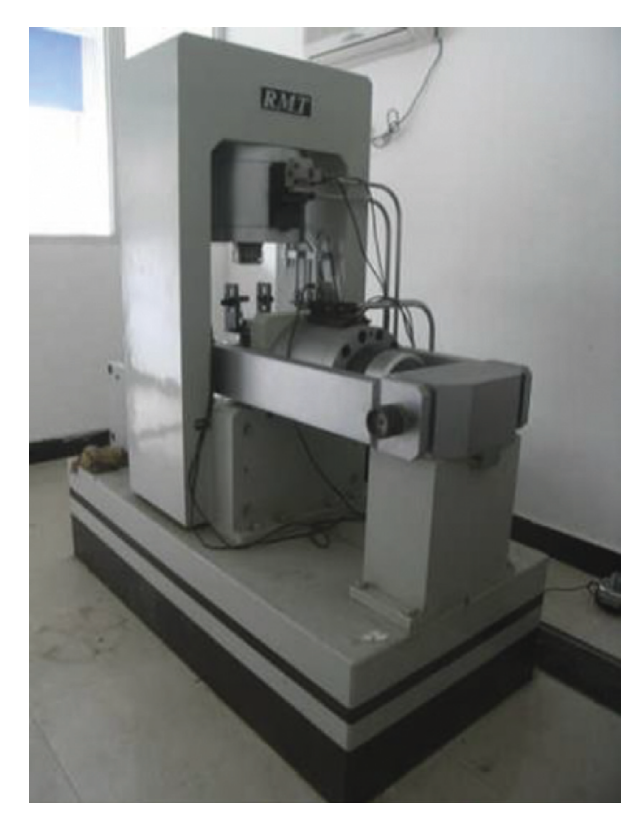

Figure 5: RMT-150CROCk Mass Zesting System.

As is depicted in Figure 9, Poisson's ratio of the rock sample increased gradually as water-rock interaction process increased. After the 1st, 2nd, 4th, 6th, 8th, and 10th cycles of immersion air-dry, Poisson's ratio increased to $4.52 \%, 8.14 \%, 13.12 \%, 16.29 \%, 17.65 \%$, and $18.55 \%$, respectively. The curve of Poisson's ratio grew fast during the first six immersion air-dry cycles and then gradually tended to be slow.

According to energy theory, the rock dynamic elastic modulus is the embodiment of dynamic elastic parameters under dynamic load, and its value reflects the quality of rock's elastic bearing performance; the rock damping ratio represents the ratio of the total energy consumed by the rock to its elastic strain energy during the single loading period. With the increase of water-rock interaction cycle, the dynamic elastic modulus gradually reduces while damping ratio increases, which indicates that under the water-rock interaction, sandstone gradually becomes soft, with internal pores and fractures being developed fast at the same time, and a single load produced more rock-dissipated energy than before. The related microstructure deterioration mechanism has been elaborated in the literature [16-19]. 


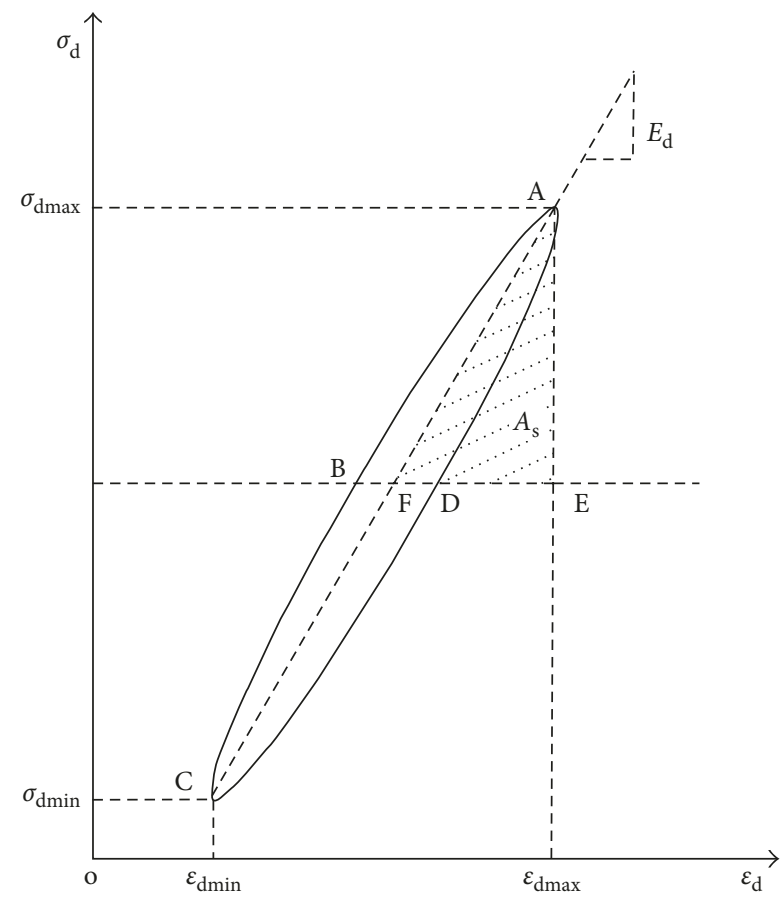

Figure 6: Hysteresis loop of dynamic strain and stress.

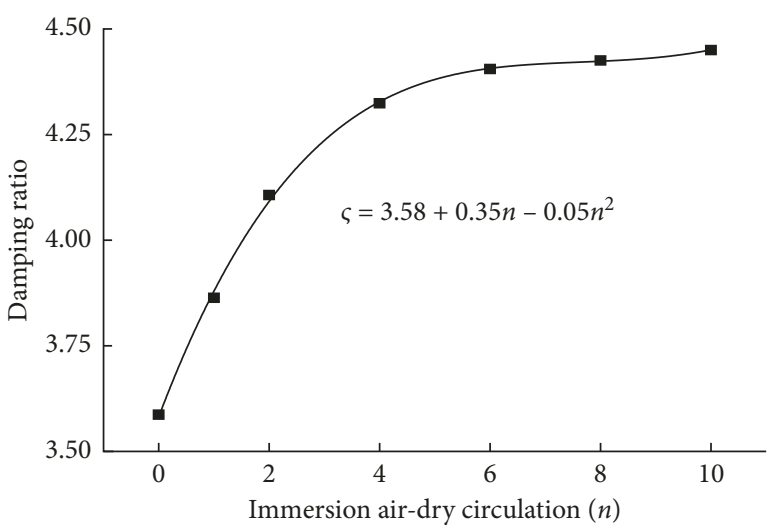

- Damping ratio

Figure 7: Sandstone damping ratio curve under water-rock interaction.

\section{Analysis of the Dynamic Response of the Bank Slope under the Water-Rock Interaction}

4.1. Slope Model. In order to analyze the dynamic response change law of the rock mass slope under the long-term water-rock interaction, a numerical simulation analysis of the typical rock slope is established, as shown in Figure 10. The area with the length, width, and height of $1000 \mathrm{~m}, 400 \mathrm{~m}$, and $10 \mathrm{~m}$, respectively, is taken for the calculation of range of slope, and the slope trailing edge length is $400 \mathrm{~m}$ with slope angle of $45^{\circ}$. The model was totally composed of 4493 nodes and 12353 units. Based on the previous study by Liu Xinrong et al [29], with the consideration of reservoir water level of $145 \mathrm{~m}$ and $175 \mathrm{~m}$, it is of great importance to analyze the dynamic response influenced by dynamic parameters

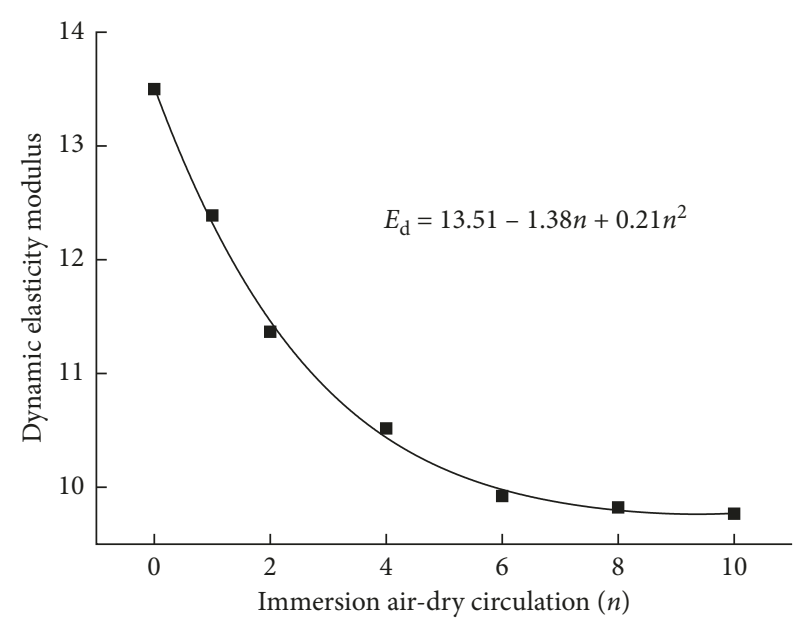

- Dynamic modulus of elasticity

Figure 8: Dynamic elasticity modulus curve of sandstone under water-rock interaction.

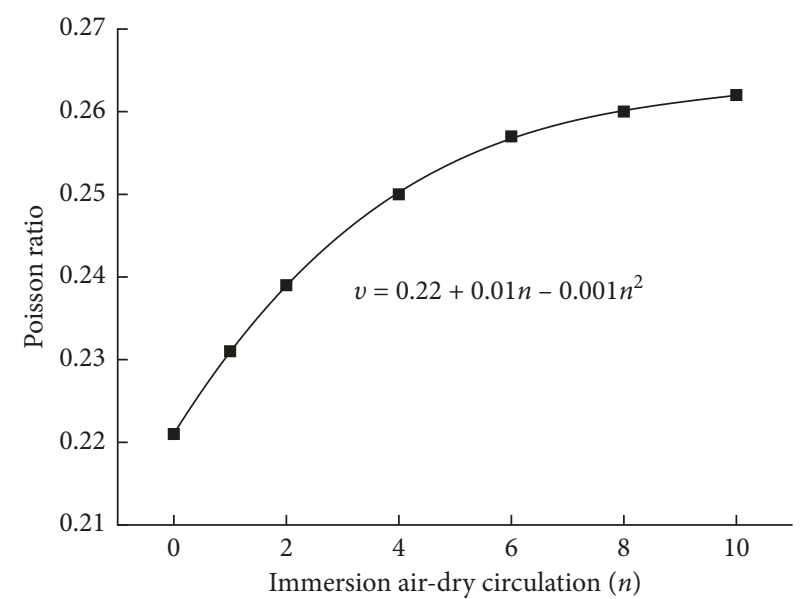

- Poisson ratio

Figure 9: Sandstone Poisson's ratio curve under water-rock interaction.

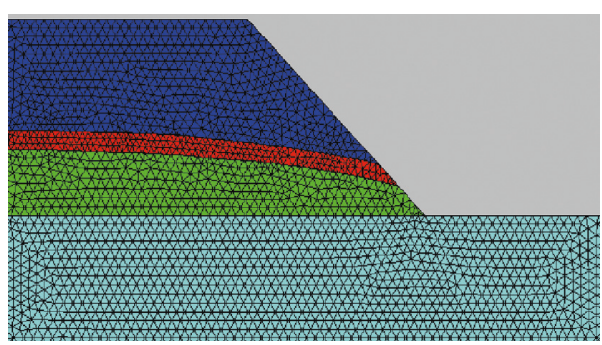

FIGURE 10: Schematic diagram of slope calculation model.

degradation in the hydro-fluctuation belt zone of the bank slope. The rock mass under the reservoir was regarded as a saturated material in the numerical simulation analysis.

According to the test results above, the dynamic parameters of slope rock mass were shown in Table 1 . In the calculation process, the corresponding values in Table 1 were 
TABLE 1: Statistics of rock mass deterioration dynamic parameters.

\begin{tabular}{lcccccc}
\hline Water-rock interaction cycle & The initial state & The 1 st cycle & The 2 nd cycle & The 4 th cycle & The 6 th cycle & The 8 th cycle The 10 th cycle \\
\hline Density $\left(\mathrm{kg} / \mathrm{m}^{3}\right)$ & 2616.08 & 2612.06 & 2608.45 & 2605.52 & 2603.18 & 2601.58 \\
Dynamic elastic modulus & 13.50 & 12.39 & 11.37 & 10.52 & 9.92 & 9.67 \\
(Gpa) & 3.59 & 3.86 & 4.11 & 4.32 & 4.41 & 4.46 \\
Damping ratio (\%) & 0.221 & 0.231 & 0.239 & 0.250 & 0.257 & 0.260 \\
Poisson's ratio & &
\end{tabular}

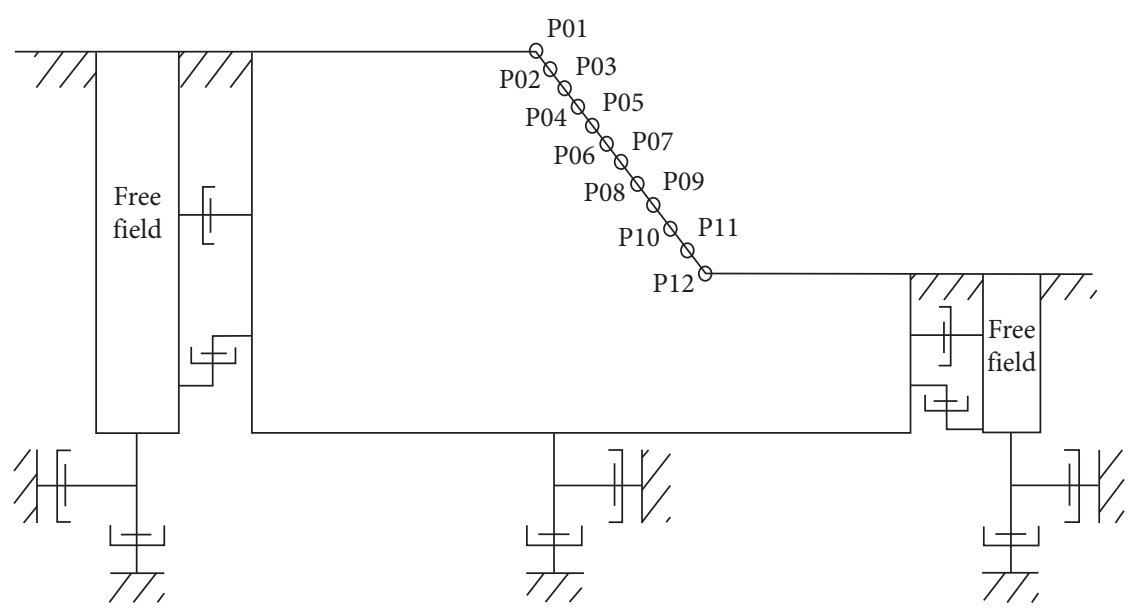

FIGURE 11: Slope dynamic analysis model and record point distribution.

used as the dynamic parameters in the hydro-fluctuation belt at different water-rock cycles, but other areas of the slope rock mass use the parameters at the initial state for all the cycles.

\subsection{Boundary Conditions and Record Point Settings.} FLAC3D uses static boundary and free field boundary in dynamic analysis. In this paper, the rock slope was selected as the study object. Due to its large value of bedrock modulus, the bottom of the slope is set as a rigid foundation for simulation processing, and free field boundary around the slope model, to make side border of the main body grid couple with the free field through the damper. In the simulation process, the rock mass in the model is regarded as an elastoplastic material with the use of local damping and the Mohr-Coulomb strength criterion. The calculation model and boundary condition settings are shown in Figure 11.

There are 12 record points set on the slope, respectively, tracking the acceleration time of each point, and their elevation and point numbers are shown in Table 2. The P01 point is at top of the slope, and P07, P08, and P09 are from the hydro-fluctuation belt area.

\section{The Seismic Dynamic Response of the Slope under the Parameter Deterioration Effect}

On the basis of previous research studies, the earthquake max magnitudes of the Three Gorges Reservoir induced by water storage ranged from 5.5 to 6 ; thus, the peak value of the horizontal acceleration is set as $0.05 \mathrm{~g}$ in this paper. After filtering and baseline correction through seismo signal, the famous El Centro seismic wave was selected as the input seismic wave, with its $30 \mathrm{~s}$ acceleration time input to FLAC3D, as is shown in Figure 12.

And the earthquake waves were put in from the bottom of the slope model, of which horizontal waves take the prime. From recent research reports, it can be found that the actual dynamic response in bank slope fits with the results of test and numerical simulation process sometimes, and the model set and parameters standard for evaluation are of great importance [30, 31].

The acceleration response and its distribution law are the basic information to evaluate the slope dynamic response. Therefore, the seismic dynamic response of the slope under the degradation condition is analyzed mainly from its acceleration response.

5.1. Dynamic Response Rules of the Bank Slope. In order to describe the slope acceleration response rule under the earthquake action, the ratio of dynamic response peak acceleration of any point in the slope body and that of point in the slope toe was defined as peak value of acceleration amplification factor (PGA). The variation rule of the horizontal direction amplification coefficient (HPGA) of each record point on the slope surface in different water-rock cycles is shown in Figure 13.

As seen in Figure 13, without considering the water-rock interaction, the HPGA of each record point of the slope increases gradually as its height rises and reaches the peak at the top of the slope. And the initial line (T0) shows the same rule as the sandstone static parameters in the slope surface. 
TABLE 2: The chart of record points and its elevation.

\begin{tabular}{|c|c|c|c|c|c|c|c|c|c|c|c|c|}
\hline Point number & P01 & P02 & $\mathrm{P} 03$ & P04 & P05 & P06 & P07 & P08 & P09 & $\mathrm{P} 10$ & P11 & $\mathrm{P} 12$ \\
\hline Corresponding elevation $(\mathrm{m})$ & 400 & 355 & 310 & 265 & 220 & 175 & 167.5 & 160 & 152.5 & 145 & 120 & 100 \\
\hline
\end{tabular}

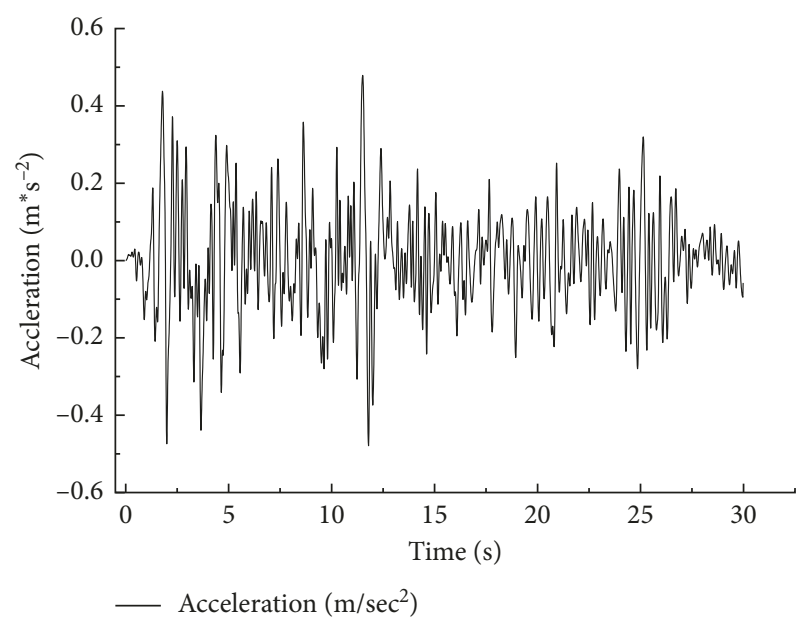

Figure 12: The time curve of input seismic acceleration.

However, its regular curve is increasing in the form of fold line, like the line of T4, which is consistent with the conclusion summarized by Zhixin Yan et al. [32].

And the variation trend of the HPGA of the record point at the top of the slope under the water-rock interaction cycle is shown in Figure 14, with that of the hydro-fluctuation belt shown in Figure 15.

When the water-rock interaction is considered, the HPGA of the record point in the hydro-fluctuation belt area increases rapidly, while that of other places in the slope decreases slowly. When the water level is $145 \mathrm{~m}$, for example, after the 1st cycle of water-rock interaction, the HPGA of the record point P07 increases from 1.23 to 1.37 , while that of the record point $\mathrm{P} 01$ goes down from 1.39 to 1.28 . It can be found that the HPGA of the hydro-fluctuation belt shows greater magnification than that of the slope top after the 10th cycle of water-rock interaction and the HPGA of record point P07 increases to 1.60 , while that of record point P01 goes down to 1.14 .

With the increase of the water-rock interaction period, the HGPA of the record points in the hydro-fluctuation belt area increases gradually with the total increase of $29.03 \%$ to $34.17 \%$ at the end of the 10th water-rock interaction cycle; the HGPA of the record points in the other area decreases gradually with the total decrease of $17.93 \%$ to $18.65 \%$ at the same time. During the first six water-rock interaction processes, the HGPA of each record point shows obvious variation trend depicted in the figures above.

With the reservoir water level of $145 \mathrm{~m}$ and $175 \mathrm{~m}$, dynamic response of bank slope share the similar law under earthquake action and so does the HPGA change law of each record point in the process of water-rock interaction. In comparison, with the water level of $145 \mathrm{~m}$, the HPGA of the record point on the slope is relatively less than that of $175 \mathrm{~m}$, and the difference between the two is about 0.05 .

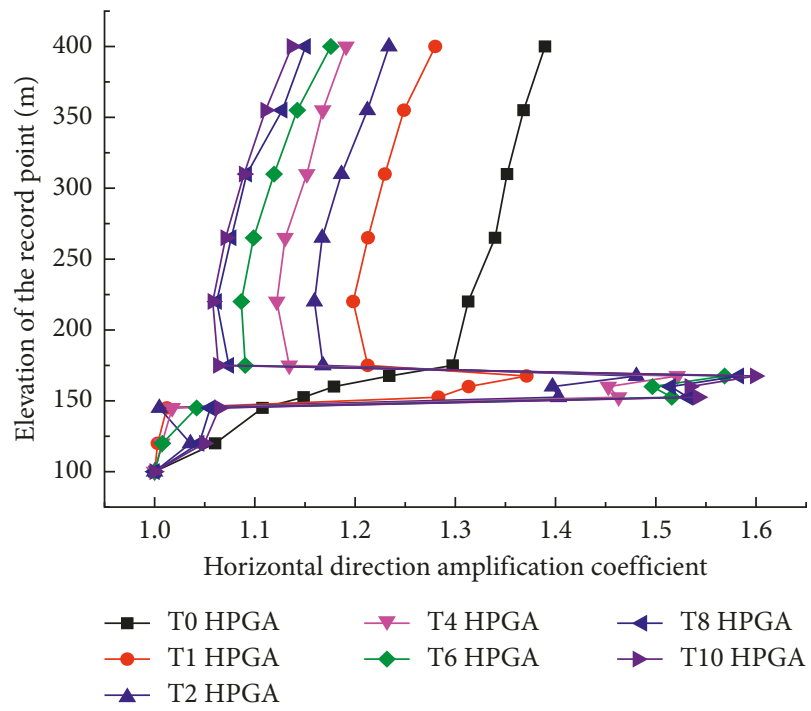

(a)

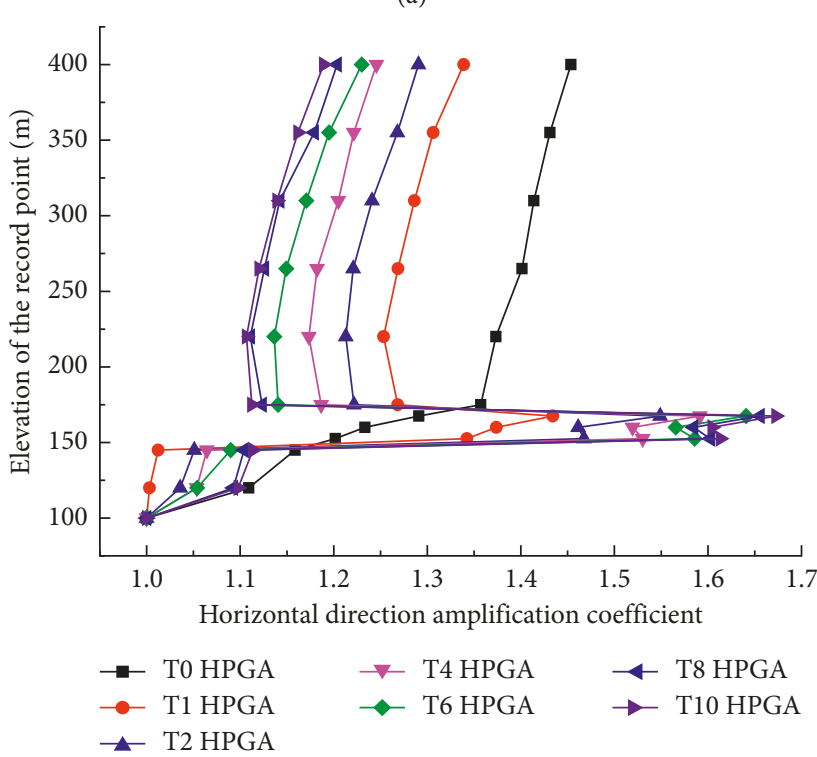

(b)

Figure 13: The HGPA variation curves of the slope surface under water-rock interaction. (a) The reservoir water level of $145 \mathrm{~m}$; (b) the reservoir water level of $175 \mathrm{~m}$.

5.2. Dynamic Response Mechanism Analysis of the Slope under Water-Rock Interaction. As seen from the results above, the main influence of water-rock interaction in the bank slope focuses on the enhanced dynamic response in the hydrofluctuation belt and the relatively weaken response of its other parts. There are two main reasons as follows:

First of all, without considering the water-rock interaction, the hydro-fluctuation belt shares the same rock properties with the other parts of the bank slope rock mass; 


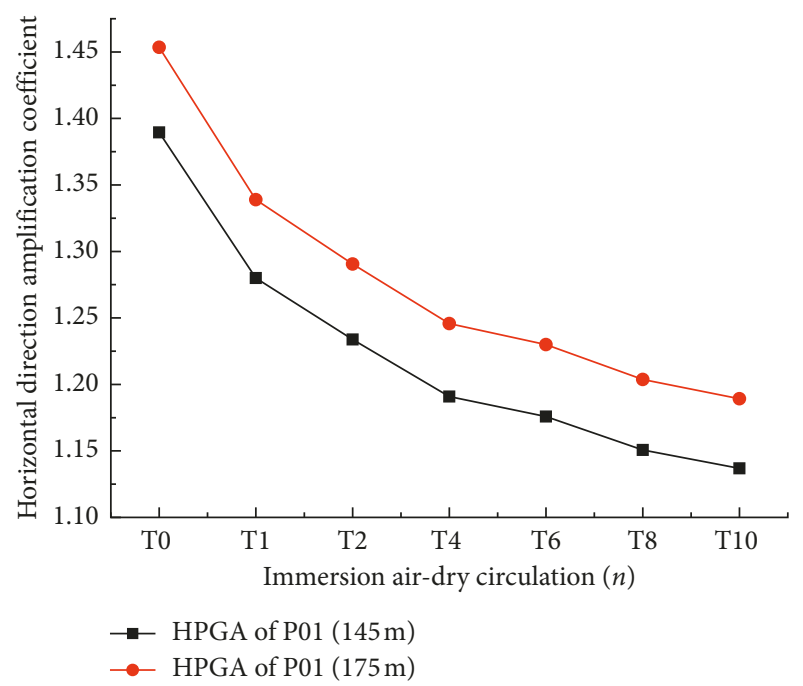

FIGURE 14: The HGPA variation curves of the slope surface under water-rock interaction with different water levels.

thus, the HPGA of the slope surface presents the similar rule to general seismic response of the slope, appeared as the top acceleration amplification effect. However, during the process of water-rock interaction, the dynamic characteristics of rock mass are gradually deteriorating under long-term immersion-air-drying alternation, with the increase of damping ratio and the damping coefficient and decrease of the dynamic elasticity modulus. Similar to the near-surface low-velocity layer of slope [33], the hydrofluctuation belt has a greater magnifying effect on the dynamic response of seismic waves than the normal slope surface, resulting in the more obvious seismic amplification effect.

Secondly, the slope shows vertical exaggeration and near-surface magnifying effect on the input seismic wave. Based on the previous studies of rock mass under higher water compression, the rock of the bank slope appeared with varied degrees of damage and destruction. After the longterm rock mass accumulation damage [34], the bank slope body dynamical response gradually strengthened, leading to slope collapse occasionally. As for the reason, it mainly concerns about the energy storage and release of rock mass. Due to the strong amplification effect of relatively lowintensity rock mass on seismic wave, according to the law of energy conservation $[35,36]$, the strong dynamic response in the hydro-fluctuation belt released much energy, leading to the relatively less energy released by the other parts, resulting in weaken dynamic response corresponding. With the dynamic parameters continued deterioration of rock mass as the water-rock interaction cycle increased, the increasing consumption and release of energy in the hydrofluctuation belt gradually weakened the acceleration response of the other parts of the slope.

\section{Conclusions}

Based on the results and analysis obtained above, the following conclusions can be made:

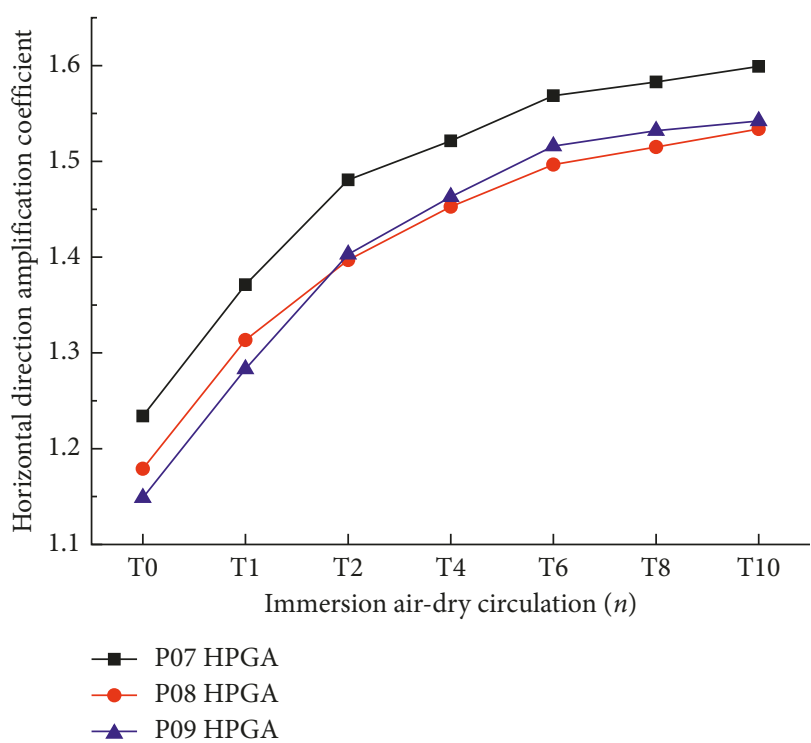

(a)

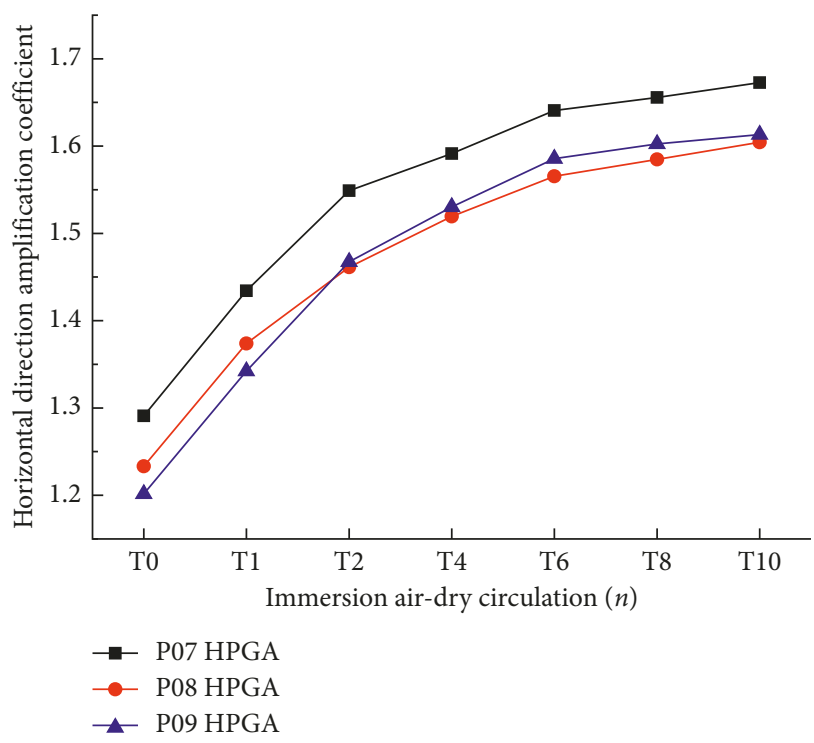

(b)

FIgURE 15: The HGPA curves of the hydro-fluctuation belt with water-rock interaction. (a) The reservoir water level of $145 \mathrm{~m}$; (b) the reservoir water level of $175 \mathrm{~m}$.

In the process of water-rock interaction, the damping ratio and Poisson's ratio of rock sample gradually increased, and the dynamic elastic modulus decreased. At the end of the 6th water-rock interaction, the variation trend of each dynamic parameter is tended to slow down, and the variable quantity of the damping ratio, dynamic elastic modulus, and Poisson ratio, under the corresponding single water-rock interaction cycle, is gradually reduced.

Without considering the water-rock interaction, the HPGA of each record point of the slope increases gradually as its height rises. When the water-rock interaction is considered, the HPGA of the record point in the hydrofluctuation belt area increases rapidly, while that of other places in the slope decreases on the whole. 
With the increase of the water-rock interaction period, the HGPA of the record points in the hydro-fluctuation belt area increases gradually, while that of the other area decreases. During the first six water-rock interaction processes, the HGPA of each record point shows obvious variation trend, and then tends to slow down in the later period.

During the process of long-term water-rock interaction, the rock mass in the hydro-fluctuation belt area of the bank slope generates accumulative damage. With the continuous degradation of its static and dynamic parameters, seismic dynamic response gradually strengthened with the increasing energy consumption, resulting in the weakened dynamic responses of the other parts of the slope.

Therefore, the hydro-fluctuation belt is the sensitive zone of the seismic dynamic response of the bank slope, which is closely related to the long-term seismic performance of the bank slope, and its protection should be strengthened in the slope prevention.

\section{Nomenclature}

$\sigma_{\max }: \quad$ Maximum dynamic stress of dynamic stress-dynamic strain hysteresis curve

$\sigma_{\min }: \quad$ Minimum dynamic stress of dynamic stress-dynamic strain hysteresis curve

$\varepsilon_{\mathrm{d} \max }:$ Maximum dynamic strain of dynamic stress-dynamic strain hysteresis curve

$\varepsilon_{\mathrm{d} \text { min }}:$ Minimum dynamic strain of dynamic stress-dynamic strain hysteresis curve

$A_{\mathrm{R}}$ : The area of $\mathrm{ABCD}$ in the hysteresis loop

$A$ : The area of the triangle AEF

$\varsigma$ : $\quad$ Damping ratio of rock sample

$E_{\mathrm{d}}$ : Dynamic elastic modulus of rock sample

$v$ : Poisson's ratio of rock sample

PGA: Peak value of acceleration amplification factor

HPGA: Horizontal peak value of acceleration amplification factor.

\section{Data Availability}

The data in this article are obtained from original laboratory tests with all the authors' help. Anyone who wants to use the data should acknowledge the provenance of the article and apply for permission from us if convenient.

\section{Conflicts of Interest}

The authors declare that there are no conflicts of interest regarding the publication of this paper.

\section{Acknowledgments}

The research was funded by National Natural Science Foundation of China (Grant no. 51439003), Natural Science Foundation of Hubei Province (Grant no. 2015CFA140), and National Natural Science Foundation of China (Grant no. 51679127), and it was also sponsored by Research Fund for Excellent Dissertation of China Three Gorges University (Grant no. 2018SSPY023).

\section{References}

[1] S. T. Wang, H. C. Liu, and Z. Y. Zhang, "Study on environmental effects of water-rock interaction in large water bodies," Geological Disasters and Environmental Protection, vol. 8, no. 1, pp. 69-88, 1997, in Chinese.

[2] L. F. Zhang, Y. S. Yao, X. L. Shen et al., "Earthquake types in the Three Gorges Reservoir: structural triggering and nonstructural induced earthquake and its mechanism," Journal of Geodesy and Geodynamics, vol. 34, no. 4, pp. 77-82, 2014, in Chinese.

[3] Y. Z. Liu, J. Ma, T. Jiang et al., "Analysis on the influence of reservoir water seepage and load on reservoir seismic formation," Seismology and Geology, vol. 32, no. 4, pp. 570-585, 2010, in Chinese.

[4] Y. L. Zhao, S. L. Luo, Y. X. Wang et al., "Numerical analysis of karst water inrush and a criterion for establishing the width of water-resistant rock pillars," Mine Water and the Environment, vol. 36, no. 4, pp. 508-519, 2017.

[5] W. T. Ma, C. P. Xu, H. O. Li et al., "The observation of induced seismic encryption in the Three Gorges Reservoir and the preliminary analysis of earthquake genesis," Seismology and Geology, vol. 32, no. 4, pp. 553-563, 2010, in Chinese.

[6] F. Dai, B. Li, N. W. Xu et al., "Analysis on microseismic characteristics of underground workshop excavation of baihetan hydropower station," Journal of Rock Mechanics and Engineering, vol. 4, pp. 692-703, 2016, in Chinese.

[7] K. M. Mu, J. Yu, and Y. Q. Zhou, "The viscoelastic deformation of surrounding rock under the consideration deterioration of pore water pressure," Journal of Railway Science and Engineering, vol. 13, no. 6, pp. 1046-1052, 2016, in Chinese.

[8] X. R. Liu, Y. Fu, Y. X. Wang et al., "Experimental study on the shear strength deterioration law of sandstone under waterrock interaction," Chinese Journal of Geotechnical Engineering, vol. 30, no. 9, pp. 1298-1302, 2008, in Chinese.

[9] Y. Fu, X. R. Liu, Y. X. Zhang et al., "Research of the water-rock interaction effect on single axial strength of sandstone," Hydrogeology and Engineering Geology, vol. 36, no. 6, pp. 54-58, 2009, in Chinese.

[10] H. Y. Yao, Z. H. Zhang, and Z. H. Zhu, "Experimental study on the influence of dry-wet alternation on the mechanical properties of sandstone," Rock and Soil Mechanics, vol. 31, no. 12 , pp. 3704-3708, 2010, in Chinese.

[11] Y. D. Jiang, C. L. Yan, and Y. X. Liu, "Experimental study on rock mechanical properties under wet and dry circulation," China Mining Magazine, vol. 20, no. 5, pp. 104-110, 2011, in Chinese.

[12] P. A. Hale and A. Shakoor, "A laboratory investigation of the effects of cyclic heating and cooling, wetting and drying, and freezing and thawing on the compressive strength of selected sandstones," Environmental and Engineering Geoscience, vol. 9, no. 2, pp. 117-130, 2003.

[13] Z. H. Zhu, P. Wu, and H. Y. Yao, "Water-drying cycle and long-term water-filled sandstone split test," International Journal Hydroelectric Energy, vol. 30, no. 12, pp. 58-60, 2012, in Chinese.

[14] F. S. Jeng, M. L. Lin, and T. H. Huang, "Wetting deterioration of soft sandstone-microscopic insights," in Proceeding of an International Conference on Geotechnical and Geological Engineering, p. 525, Melbourne, VIC, Australia, November 2000. 
[15] M. L. Lin, F. S. Jeng, L. S. Tsai et al., "Wetting weakening of tertiary sandstones-microscopic mechanism," Environmental Geology, vol. 48, no. 2, pp. 265-275, 2005.

[16] H. F. Deng, J. L. Li, K. W. Wang et al., "Research on secondary porosity changing law of sandstone under saturation-air dry cycles," Rock and Soil Mechanics, vol. 33, no. 2, pp. 483-488, 2012, in Chinese.

[17] H. F. Deng, J. L. Li, M. Zhu et al., "Experimental research on strength deterioration rules of sandstone under "saturationair dry" circulation function," Rock and Soil Mechanics, vol. 33, no. 11, pp. 3306-3312, 2012, in Chinese.

[18] H. F. Deng, M. L. Zhou, J. L. Li et al., "Creep degradation mechanism by water-rock interaction in the red-layer soft rock," Arabian Journal of Geosciences, vol. 9, no. 12, pp. 1-12, 2016.

[19] H. F. Deng, X. F. Yuan, L. H. Wang et al., "Experimental research on changes in the mechanical property law of reservoir bank sandstone under "immersion-air dry" circulation," Environmental Engineering and Management Journal, vol. 12, no. 9, pp. 1785-1789, 2013.

[20] X. L. Wan and D. Y. Xi, "The dynamic response of saturated sandstone by cyclic loading," Computing Techniques for Geophysical and Geochemical Exploration, vol. 31, no. 5, pp. 417-410, 2009, in Chinese.

[21] D. T. Xi and J. H. Huang, "Preliminary study on the land resources of the Three Gorges Reservoir," Resources and Environment of the Yangtze River Basin, vol. 8, no. 1, pp. 75-80, 1999, in Chinese.

[22] Q. J. Xu and Y. Lu, "The effect of wet and dry alternation on the long-term safety of slope," Journal of Underground Space and Engineering, vol. 1, no. 6, pp. 1021-1024, 2005, in Chinese.

[23] Y. Guo, C. Yang, L. Wang, and F. Fu, "Effects of cyclic loading on the mechanical properties of mature bedding shall," Advances in Civil Engineering, vol. 2018, Article ID 8985973, 9 pages, 2018.

[24] Y. X. Wang, P. P. Guo, W. X. Ren et al., "Laboratory investigation on strength characteristics of expansive soil treated with jute fiber reinforcement," International Journal of Geomechanics, vol. 17, no. 11, article 04017101, 2017.

[25] Y. L. Zhao, Y. X. Wang, W. J. Wang, W. Wan, and J. Tang, "Modeling of non-linear rheological behavior of hard rock using triaxial rheological experiment," International Journal of Rock Mechanics and Mining Sciences, vol. 93, pp. 66-75, 2017.

[26] Y. L. Zhao, Y. X. Wang, W. J. Wang, C. Pu, W. Wan, and J. Tang, "Cracking and stress-strain behavior of rock-like material containing two flaws under uniaxial compression," Rock Mechanics and Rock Engineering, vol. 49, no. 7, pp. 2665-2687, 2016.

[27] D. Y. Xi, Y. W. Xue, and X. L. Wan, "The damage of saturated sandstones under cyclic loading," Computing Techniques for Geophysical and Geochemical Exploration, vol. 24, no. 3, pp. 193-198, 2004, in Chinese.

[28] J. F. Liu, J Xu, Q. S. Li et al., "Experimental research on damping parameters of rock under cyclic loading," Chinese Journal of Rock Mechanics and Engineering, vol. 29, no. 5, pp. 1036-1041, 2010.

[29] X. R. Liu, Y. Fu, Y. X. Wang et al., "The effect of bank slope stability under water-rock interaction," Rock and Soil Mechanics, vol. 30, no. 3, pp. 613-616, 2009, in Chinese.

[30] A. N. Tutuncu, A. L. Podio, and M. M. Sharma, "Nonlinear visco-elastic behavior of sedimentary rocks, part I: effect of frequency and strain amplitude," Geophysics, vol. 63, no. 1, pp. 184-190, 1998.
[31] A. N. Tutuncu, A. L. Podio, and M. M. Sharma, "Nonlinear visco-elastic behavior of sedimentary rocks, part II: hysteresis effect and influence of type of fluid on elastic moduli," Geophysics, vol. 63, no. 1, pp. 195-203, 1998.

[32] Z. X. Yan, L. P. Zhang, X. H. Cao et al., "Study on dynamic response and deformation mechanism of bedding rock slope under earthquake action," Chinese Journal of Geotechnical Engineering, vol. 33, no. s1, pp. 61-65, 2011.

[33] R. Q. Huang and J. S. Yu, "Simulation study on the influence of weak interlayer characteristics on seismic wave strength," Journal of Engineering Geology, vol. 3, pp. 312-317, 2003.

[34] S. J. Wang, F. S. Ma, and Y. L. Du, "Water-rock interaction and its geological environment effect in reservoir area," Journal of Engineering Geology, vol. 4, no. 3, pp. 1-9, 1996, in Chinese.

[35] H. F. Deng, J. L. Li, C. J. Deng et al., "Analysis of sampling in rock mechanics test and compressive strength prediction methods," Rock and Soil Mechanics, vol. 32, no. 11, pp. 3399-3403, 2011, in Chinese.

[36] F. Q. Gong, S. Luo, X. B. Li et al., "The law of linear energy storage and energy consumption in red sandstone tensile failure," Journal of Rock Mechanics and Engineering, vol. 37, no. 2, pp. 352-363, 2018, in Chinese. 


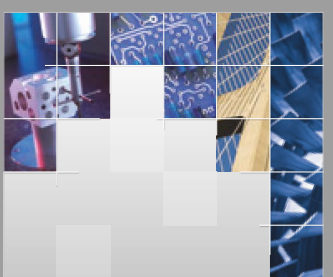

\section{Enfincering}
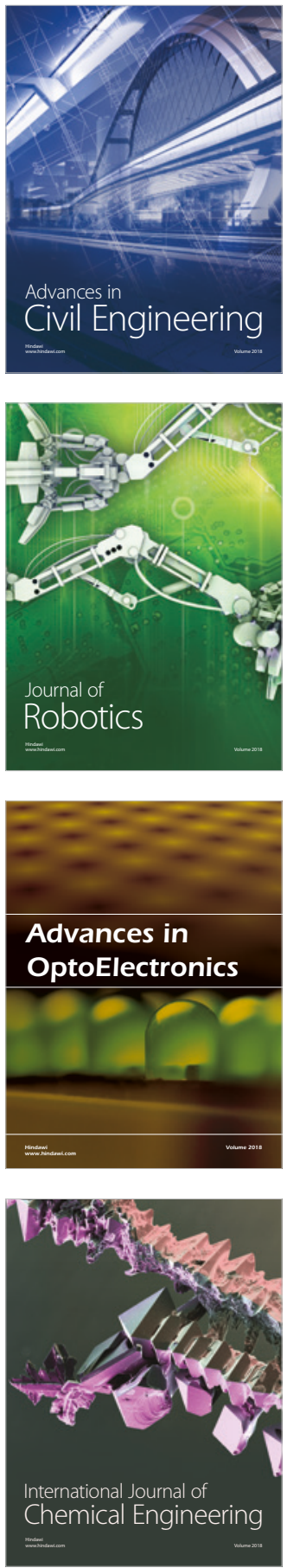

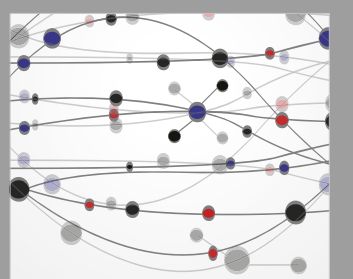

\section{Rotating \\ Machinery}

The Scientific World Journal

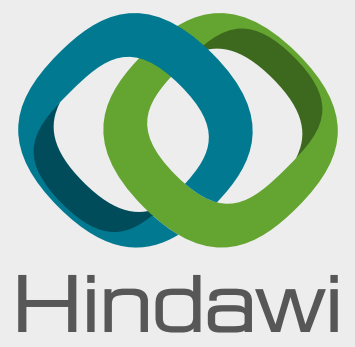

Submit your manuscripts at

www.hindawi.com
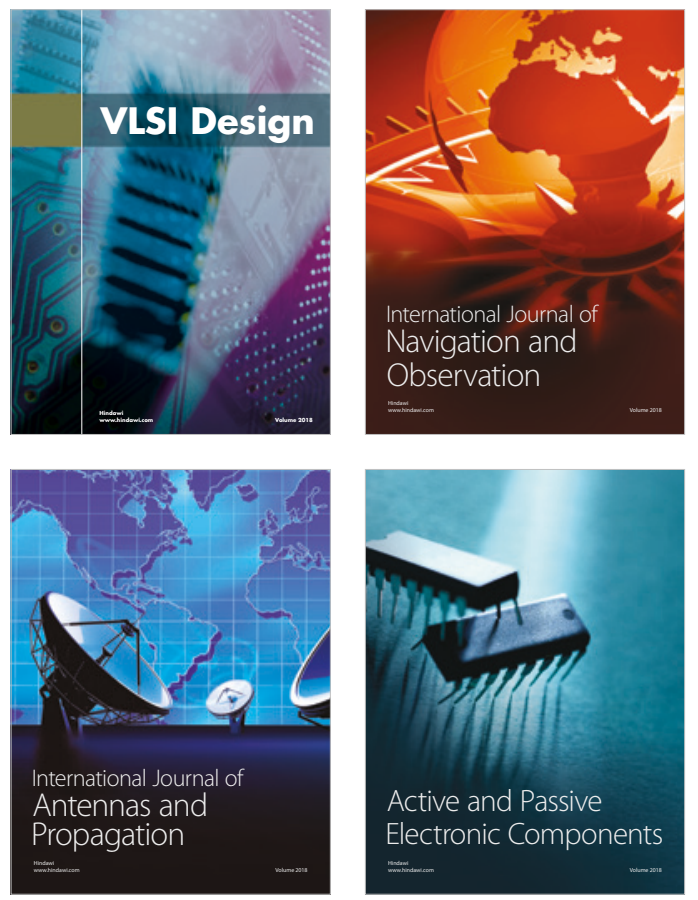
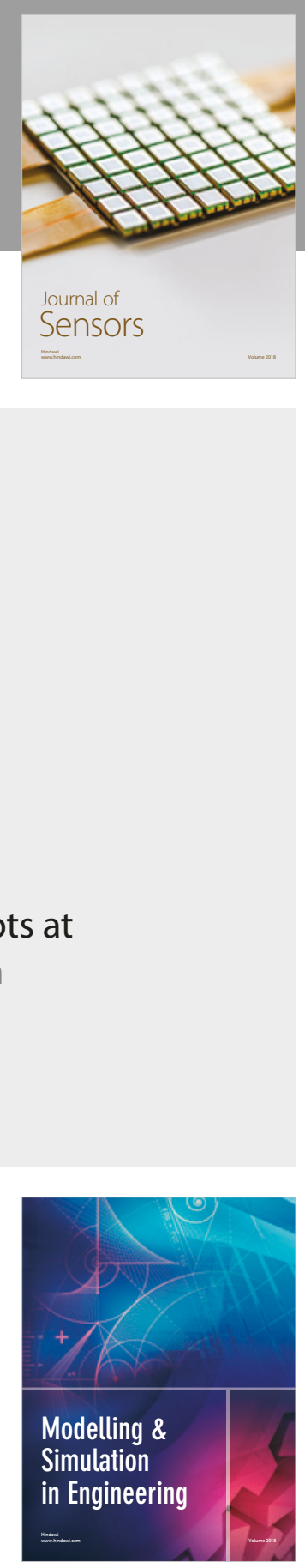

\section{Advances \\ Multimedia}
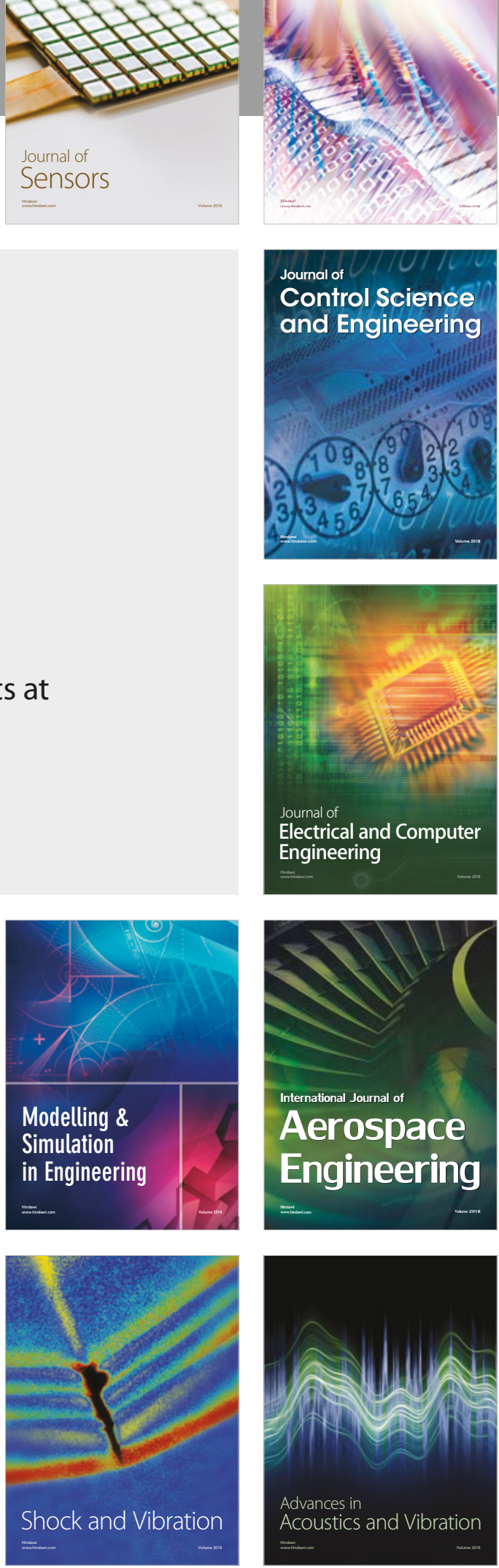